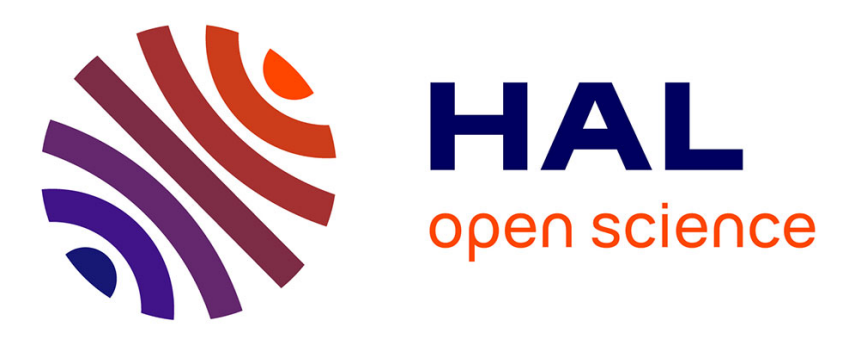

\title{
Study of the Relations between Instrumentist and Instrument in Computer Music
}

\author{
Claude Cadoz, Annie Luciani
}

\section{To cite this version:}

Claude Cadoz, Annie Luciani. Study of the Relations between Instrumentist and Instrument in Computer Music. 101st Meeting of the Acoustical Society of America, 1981, Ottawa, Canada. pp.11. hal-00910635

\section{HAL Id: hal-00910635 https://hal.science/hal-00910635}

Submitted on 10 Jun 2014

HAL is a multi-disciplinary open access archive for the deposit and dissemination of scientific research documents, whether they are published or not. The documents may come from teaching and research institutions in France or abroad, or from public or private research centers.
L'archive ouverte pluridisciplinaire HAL, est destinée au dépôt et à la diffusion de documents scientifiques de niveau recherche, publiés ou non, émanant des établissements d'enseignement et de recherche français ou étrangers, des laboratoires publics ou privés. 
101st Meeting. OTTAWA

Wed. 20 May 1981

C. CADOZ, A.LUCIANI

A.C.R.0.E. Laboratoire de la communication Parlée ENSERG, 23 Av. des Martyrs 38031 GRENOBLE CEDEX, FRANCE

STUDY OF THE RELATIONS BETWEEN INSTRUMENTIST AND INSTRUMENT IN COMPUTEUR MUSIC.

The use of the computer for musical purposes

began in the late 1950s.

From the very beginning of computer music we observe several attitudes which are different by their principles and their goals. However the two most significant are probably AUTOMATIQUE COMPOSITION and DIRECT SYNTHESIS of SOUNDS.

With regard to Automatique Composition we must

mention Hiller and Isacson and their "Illiac suite". for string quartet composed with a computer in 1956.

Direct sound synthesis was introduced and developed in the 1960 s by Max Mathews and his team at the Bell Telephone Laboratories, with the Music $V$ programs family.

Although we must consider these attitudes with equal importance, we shall be concerned here only with the second as it is our own starting point.

Digital synthesis of sounds, to our mind, is laying out more significantly the problem of the 'musical creation tool' as it approaches the musical sound in its very elements without excluding the means of its composition in complex structures and musical pieces. 
Some keywords can help us to draw quickly the evolution of sound synthesis:

First, analogue and digital technologies.

It is sometimes not realized that computer sound synthesis is nearly as old as electronic music itself. Through the transition from the analogue processes to digital ones, sound synthesis has gained on several fundamental points: far greater precision, facilities for unlimited combining of unit generators as they are only software objects.

However, the computer sound synthesis programs did not generally operate in real-time, and a user had to wait until a complete section had been synthesized before he could listen to it.

Thanks to the spectacular evolution of digital microcircuitry, digital synthesizers were developed during the $1970 \mathrm{~s}$. These combine the advantages of digital sound synthesis with the real-time facilities and allow the user to modify parameters interactively while the sound is being produced, using linear and rotary potentiometers, keyboards and similar devices.

In parallel with the evolution of hardware aspects, the general purpose langages have been improved as they were needed by musicians and composers to develop their own musical langages.

Nevertheless, we must observe that during these consecutive evolutions, the basic and initial principles remained the same. The central object of synthesis is the sound object which is decomposed in its acoustical components: waveform, envelope, amplitude, frequency, spectrum and so on. Whether in the analogue or in the digital technologies, we find the same elementary functions: oscillators, envelop shapers, filters, and the same basic processes: parameter modulations such as amplitude or frequency modulation. 
So, without regard for the technologies and the improvments of methods, a single term may resume all these attitudes: ACOUSTICAL SYNTHESIS.

Concerning our own approach, we first introduce a criticism of Acoustical synthesis as a basic means to built a musical creation tool in the computer context. In order to avoid a too long explanation we shall simply say that Acoustical Synthesis materializes an abstract system: the Acoustics, which enter into a relationship with the musical experience only later on. So, digital synthesis opens up a theoritically unlimited field-and this is the most important point the digital synthesis has brought us- nevertheless it appears that essential features which made "ancestral machines" such as traditional instruments so efficient, have been lost: The possibility of the elementary concrete experiment which determines the first links between the sound object and its significance.

Our attitude starts with the hypothesis that the first approach of a musical creation tool must be of an instrumental kind. Acoustical synthesis, although it allows a control of the sound from its very elements to complex structures, corresponds mainly and exclusively to compositionnal approach.

So, to built a creation tool, we suppose in our approach, a first stage where are taken into account all the conditions which allow the human-machine relation to be an instrumental experimentation. 
We may consider the computer, in Acoustical Synthesis, as a means of representation, in a primordial sense. So it is a means to represent the sound object itself. Our approach then consists in leaving the sound as a central object and substituting it with the representation of its causality: the instrument in its complete concrete definition.

What about instrument and instrumental experimentation?

The instrument is first a concrete object, more precisely, between the instrumentist and the instrument there is a multisensory relation: at least three sensory channels are implicated:

- acoustical,

- visual,

and also a very important, one which we might call the gestual channel.

The gestual channel is peculiar since it is simultaneously a transmitter and a receiver: A transmitter as it is the means by which the operator communicates information to the instrument object; the latter converts gestual, in fact mechanical information into acoustical information.

A receiver by the fact that it informs the operator of phenomena which are neither acoustical nor visual: the weight, the surface state of the object, its resistance to displacements, its articulations ...

This information has an important incidence on the playing, and are integrating part of the instrumentist-instrument relationship.

Another feature in the instrumental experience is the real-time relation between the gestual action and the three feed-back responses (acoustical, visual and gestual ones) In the primitive stade, if we consider it from a theorical point of view, both the relation between gestual action and sensory responses, on the one hand, and the co-ordination between each specific response on the other, are unknown. This discovery results from a first experiment.

In a situation where the sound event is completely unheard of, it cannot have another significance than its causality: the instrument object which it comes from. The instrument object therefore, must be understood in a large sense, not only with reference to the traditional instruments, then it plays a 
prominent part in the birth of symbolic process.

We have developed a system which will be able to offer these instrumental conditions in the context of a digital representation. 
The representation of multisensory objects and, in a first step, of objects with acoustical and gestual aspects implies two kinks of specific functions:

First, in addition to the common transducers such as loud speakers associeted with digital to analog converters and amplifiers, a special transducer which must take into account the bilateral aspect of the gestual channel. We call this a 'gestual transducer with mechanical feadback'. The study and building of such transducers are an important part of our research.

Second, a simulating system which co-ordonates the different signals to be sent or received by the computer in such a way that they correspond to a consistent object.

I am going first to speak quickly about the CORDIS program which is the simulating system we have develope in our research group in Grenoble.

It is founded on a mechanical modelisation of essential parts of the instrument. The instrument is decomposed into two components: the excitor and the vibrating structure.

The excitor is the mechanical structure which transforms gestual functions (varying forces and displacements) into excitation functions which directly apply to the vibrating corps.

For example, in traditional instruments, excitors are more or less complex mechanisms such as piano mechanisms, drumsticks, stringinstrument bows and so on...

The vibrating structure is the reunion of all the parts which have a vibrating motion producing a sound. In traditional instruments, vibrating structures are made of one or several combined elements such as vibrating strings, surfaces or volumes.

The CORDIS. system sets the digital algorithms representing three basic mechanical elements: ponctual mass, stiffness and friction, and their combination. It gives also a means of studying several simple discontinuous processes.

With a convenient langage the operator can built any complex mechanical structure with the same elements both 
for the excitor and the vibrating structure, without studying the mechanical equations.

transducers.

I now come to the second part: the gestual

We have built two prototypes of gestual transducers with mechanical feed-back. The second has the dimensions of a piano key with, however a deeper course.

slide 1 shows this device. We can see, as explained on the second sijde, the three functional components:

- two sensors: a force sensor and a displacement sensor, which pick up the gesture information developed in a single freedom degree. These two functions corresponds to the transmitter aspect.

- The receiver function or mechanical feed-back, is assumed by the third component: a torque motor whose entry current is controled by the processor.

In connection with the coRDIS program and by using analogue to digital and digital to analogue converters, we can simulate a complete physical object which is manipulated and perceived by the operator.

Let me present to you now a short movie sequence showing a use of this device in a study of only the gestual aspects.

It is indeed of a particular interest, in a first stage, to separate the three main sensory loopsand to study each one for itself:

- the gestual to sound loop,

- the gestual to visual loop,

- and the gestual to gestual loop.

The film shows a simulation of a simple mechanism as it is descibed in the third slide. 
A ponctual mass $M$ is linked to a fixed reference with two elements:

- a linear spring with $K$ as the stiffness parameter,

- a friction element with $Z$ as another parameter.

We can vary these parameters directly by changing the data

on the run time in the CORDIS program.

In a first sequence, we increase $K$, Whereas $Z$ is maintained constant. We observe then the key becoming more and more unstable, with self oscillations.

In a second sequence, $K$ is constant and we increase $Z$. We observe a variation of the key motion and consequently an evolution in the kind of gesture.

In the third sequence, there is a nul value for $K$ and an important value for the friction parameter. The free position of the key is :... then undetermined and it is left in the state it was in when we released it. 
What I have shown here is a starting point.

However it seemed important to me to present some basic principles of an approach which is quite different from the usual ones.

The global attitude evoked here still requires, before reaching its very operational state with regard to musical creation, many developments and experimentations.

The first step we have reached now is the completion of a global software and hardware system including all the minimal conditions for an instrumental relationship.

The first experiments to be carried out concern multisensory perception at an elementary level, in particular perception tests on the subjective mutual influence that sensory channels exert upon each other.

For example, sound events that are objectively identical, may produce different subjective perceptions if they are the responses to gestual actior which differ.

This subjective interaction can be, in its principle, generalised for each pair of channels and for the three fundamental ones

all put together. 


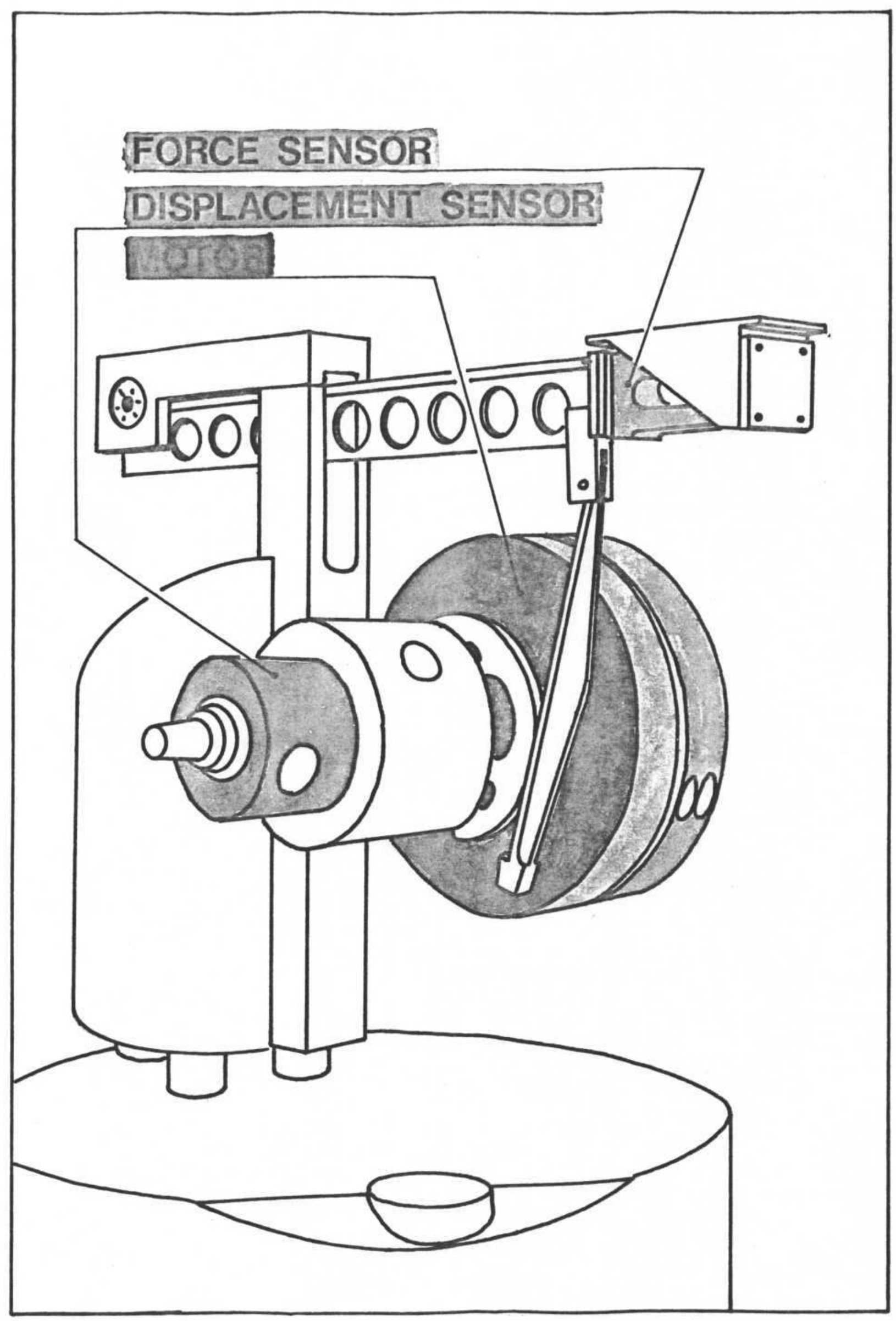




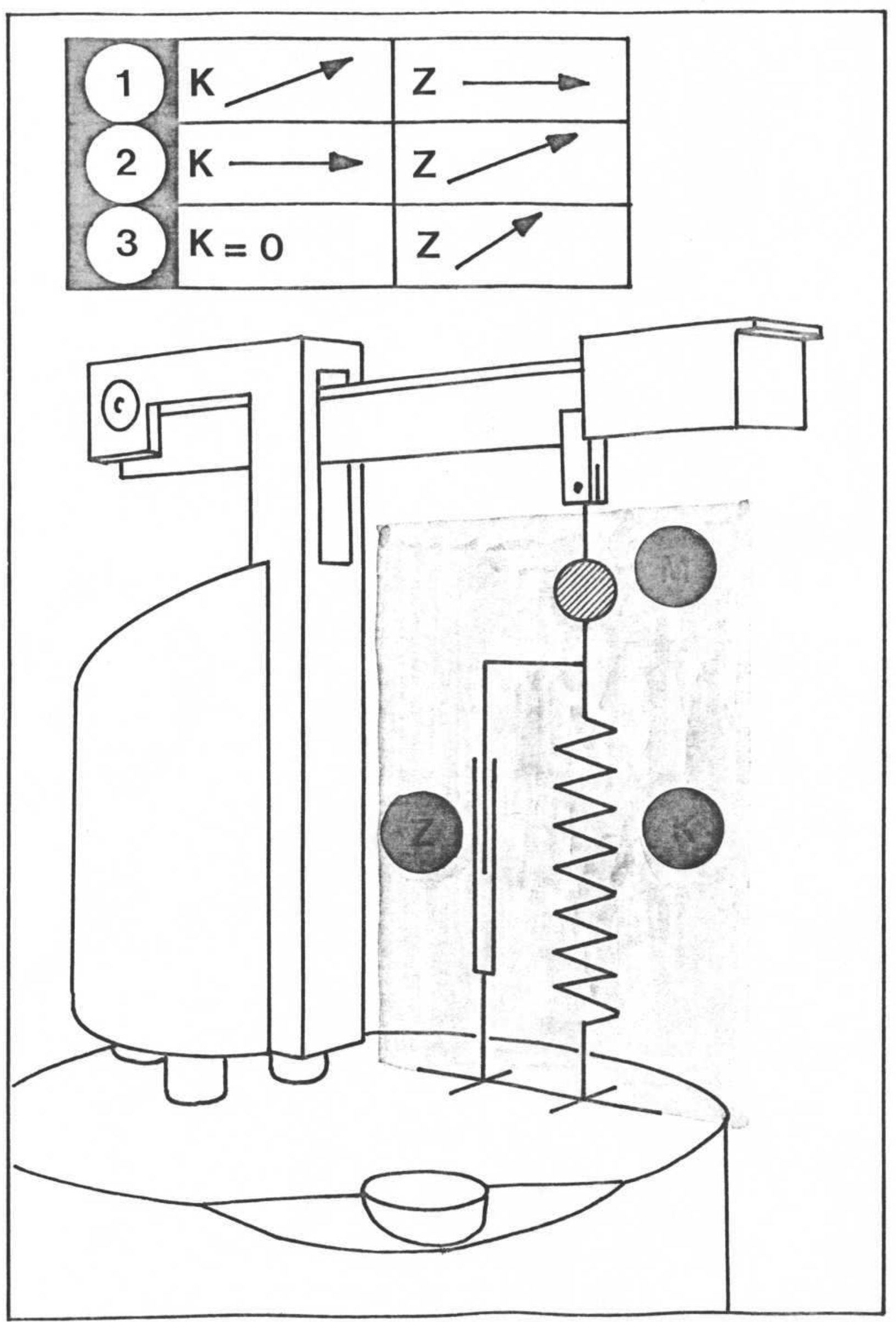

